\title{
A Retrospective Clinical Comparison of Two Allogeneic Bone Matrices Containing Viable Osteogenic Cells in Patients Undergoing Foot and/or Ankle Arthrodesis
}

\author{
Jeff D Loveland ${ }^{1 *}$, Erik I Waldorff ${ }^{2}$, David $\mathrm{Y} \mathrm{He}^{3}$ and Brent L Atkinson ${ }^{4}$ \\ ${ }^{1}$ Central Tennessee Foot and Ankle Center, Sparta, TN, USA \\ ${ }^{2}$ Orthofix, Inc., Lewisville, TX, USA \\ ${ }^{3}$ Analytical Solutions Group, Inc. North Potomac, MD, USA \\ ${ }^{4}$ Atkinson Biologics Consulting LLC, Highlands Ranch, CO, USA
}

\section{Abstract}

Background: Cellular bone allograft possesses the osteogenic, osteoinductive, and osteoconductive elements essential for bone healing. The purpose of this study was to compare the fusion rates of two cellular bone allografts that differ in the minimum number of inherent osteogenic cells for foot and/or ankle arthrodeses.

Methods: A retrospective comparative evaluation of patients treated with Trinity Evolution ${ }^{\circledR}$ and Trinity ELITE ${ }^{\circledR}$ was performed. At baseline and at 3,6 and 12 months, standard radiographs were taken to evaluate the fusion status. The study population consisted of 75 subjects and 141 total arthrodeses.

Results: At 3,6 and 12 months, the fusion rate was $57.3,79.4$ and $93.3 \%$ of subjects and $58.9,83.9$ and $95.7 \%$ of joints, respectively, for the combined Trinity Evolution and Trinity ELITE group. There were no significant differences in fusion rates observed between these grafts at any timepoint. Certain subjects with risk factors (e.g. diabetic, obese, elderly) had fusion rates comparable to normal patients. Fusion rates using these grafts were not adversely affected by several risk factors.

Conclusions: Both Trinity Evolution and Trinity Elite effectively achieve fusion in patients with compromised bone healing and provides safety and effectiveness in foot and/or ankle arthrodeses. These cellular bone allografts appear to have the minimum threshold number of cells that are required to achieve a successful fusion.

Trial registration: Not required for retrospective studies.

Keywords: Allograft; Stem cell; Foot and/or ankle fusion; Cellular bone allograft; Trinity Evolution ${ }^{\circledR}$; Trinity ELITE ${ }^{\circledR}$

\section{List of Abbreviations}

BMP: Bone Morphogenetic Protein; CBA: Cellular Bone Allograft; CT: Computed Tomography; MSC: Mesenchymal Stem Cell; OPC: Osteoprogenitor Cell; $\mathrm{T}_{\mathrm{EV}}$ : Trinity Evolution; $\mathrm{T}_{\mathrm{EL}}$ : Trinity Elite

\section{Background}

An aging population and contributory comorbidities have led to a dramatic increase in foot and ankle arthrodeses from 1990 to 2007 [1] and the trend is expected to continue [2]. Foot and ankle arthrodesis is routinely utilized to decrease pain and reverse the disability associated with arthritis, trauma, instability, diabetes and malalignment [3-5]. Failed arthrodeses are frequently associated with numerous risk factors including diabetes mellitus, tobacco use, osteoporosis, non-steroidal antiinflammatory drugs, increased age, and high body mass index [6-8].

Autologous corticocancellous bone graft (autograft) placed between the joint surfaces to be fused, has historically been the gold standard in procedures that require bone grafting [9-11]. However, harvesting autograft bone results in well-known complications [12-15] and the bone quality can be poor especially in older individuals or patients with significant comorbidities [16,17]. Cellular bone allografts (CBA) are comparable to autograft in that both share the three characteristics that are required for effective bone formation, an osteoconductive scaffold, osteoinductive growth factors and osteogenic cells, while CBA eliminates the surgical step for autograft recovery.

Previously, one CBA, Trinity Evolution ${ }^{\circledR}\left(\mathrm{T}_{\mathrm{EV}}\right)$ has been evaluated as an adjunct for foot and ankle arthrodesis in a prospective multicenter study of 76 patients [18]. The fusion rate using $\mathrm{T}_{\mathrm{EV}}$ was higher than or comparable to historical autograft fusion rates and was not adversely affected by several high-risk patient factors [18]. A new form of CBA, Trinity $\operatorname{ELITE}^{\circledast}\left(\mathrm{T}_{\mathrm{FL}}\right)$, was subsequently developed that contains a validated, minimum cell number that is two-fold greater than $\mathrm{T}_{\mathrm{EV}}$

The purpose of this study was to compare the fusion rate of two CBA products and the null hypothesis was that there would be no difference in fusion rates. The primary aim was to evaluate fusion rates between the two CBA products and a secondary aim was to assess fusion rates between normal subjects and subjects with risk factors. A retrospective study was performed on a population of subjects requiring a variety of foot and/or ankle arthrodeses to compare fusion rate outcomes.

\section{Methods}

\section{Aims and study design}

The primary aim of this study was to evaluate fusion rates between

*Corresponding author: Loveland JD, Central Tennessee Foot and Ankle Center, 415 Sewell Road, Sparta, TN 38583, USA, Tel: 931-738-1026; Fax: 931 738-1027; E-mail: lovelanddpm@yahoo.com

Received October 20, 2017; Accepted October 25, 2017; Published October 31 2017

Citation: Loveland JD, Waldorff EI, He DY, Atkinson BL (2017) A Retrospective Clinical Comparison of Two Allogeneic Bone Matrices Containing Viable Osteogenic Cells in Patients Undergoing Foot and/or Ankle Arthrodesis. J Stem Cell Res Ther 7 : 405. doi: 10.4172/2157-7633.1000405

Copyright: (c) 2017 Loveland JD, et al. This is an open-access article distributed under the terms of the Creative Commons Attribution License, which permits unrestricted use, distribution, and reproduction in any medium, provided the original author and source are credited. 
the two CBA products and a secondary aim was to assess fusion rates between normal subjects and subjects with risk factors (defined by those with diabetes, high weight status, age 65 years or older and nicotine users). A retrospective clinical evaluation using two Cellular Bone Allografts (CBA) was performed in subjects undergoing foot and/or ankle arthrodeses according to Good Clinical Practice requirements. The Institutional Review Board approved the study and informed consent was waived for subjects.

Subjects were enrolled at the author's (JDL) institution and were included into the study if they were at least 18 years of age and had received an ankle, subtalar, talo-navicular or mid-foot arthrodesis using CBA. No restrictions were placed on the diagnosis, which included osteoarthritis, trauma, deformity, Charcot neuropathy, and revision surgeries. Exclusion criteria included the use of any concomitant bone graft or bone graft substitute product, adjunctive post-operative bone growth stimulation, acute local or systemic infection, sepsis at the time of surgery or prisoners at the time of surgery.

Seventy-five subjects that completed the one year follow-up visit were retrospectively enrolled in the study. Surgeries were performed in the six-year interval between January 2009 and December 2014. The surgeon employed standard operative technique for access to the operative site and for the preparation of opposing joint surfaces, instrumentation and postoperative care. The preparation of Trinity Evolution $^{\circledR}\left(\mathrm{T}_{\mathrm{EV}}\right)$ or Trinity ELITE ${ }^{\circledR}\left(\mathrm{T}_{\mathrm{EL}}\right)$ (Orthofix, Inc., Lewisville, TX, processed by Musculoskeletal Transplant Foundation, Edison, NJ) in the operating room prior to implantation was standardized as previously described [19]. $\mathrm{T}_{\mathrm{EV}}$ and $\mathrm{T}_{\mathrm{EL}}$ are similar in that they both are comprised of human tissue that contains viable cells within a cancellous bone scaffold and a demineralized bone component, although the demineralized bone component is different. $\mathrm{T}_{\mathrm{EL}}$ contains entangled demineralized bone fibers whereas $T_{E V}$ contains demineralized bone particles, thereby allowing $\mathrm{T}_{\mathrm{EL}}$ to be more resistant to irrigation and to be more densely packed into defect sites. $\mathrm{T}_{\mathrm{EL}}$ also differs by having a minimum specification for total cell number and mesenchymal stem cells (MSCs) and/ or osteoprogenitor cells (OPCs) that is 2-fold greater than $\mathrm{T}_{\mathrm{EV}}(\geq$ $100,000 / \mathrm{cc}$ versus $\geq 50,000 / \mathrm{cc}$ cells, respectively). The graft was placed between opposing subchondral joint surfaces following preparation and the volume was recorded. No autograft or other bone graft substitute was placed. The two CBAs were not combined in any subject. Because of product availability, $\mathrm{T}_{\mathrm{EV}}$ was placed in the first 44 subjects followed by $\mathrm{T}_{\mathrm{EL}}$ placed in the subsequent 31 subjects.

Retrospective analysis was based on three postoperative visits that were performed at 3 ( \pm 45 days), 6 ( \pm 45 days) and 12 ( \pm 4 ) months. At each time point, the investigator obtained adverse event information and routine radiographs, which included three views of the foot and/or ankle (AP, lateral and oblique).

\section{End points}

The primary end point was to assess the fusion status at 3, 6 and 12 months. The secondary end point was to measure clinical outcomes as assessed by incidence of adverse reactions. Safety information was collected in accordance with FDA regulations and included recording both the number of adverse events and the investigator evaluation of severity and possible relationship of the adverse events to the treatment.

\section{Radiographic analysis}

At 3, 6 and 12 months, fusion was assessed by the investigator from three views of standard radiographs (AP, lateral and oblique). Successful individual joint fusion required the presence of greater than $50 \%$ bridging bone across the joint in at least one of the views as previously defined in an FDA regulated clinical study of foot and ankle arthrodesis [2]. Successful overall fusion for the subject required that each joint be fused. In 11 and 13 cases at 3 and 6 months, respectively, Computed Tomography (CT) was also performed due to suspected non-union based on X-rays. CT was not used to assess fusion status.

\section{Statistical analysis}

Statistical analyses were performed to evaluate fusion rate between two CBA products and to determine the association between fusion and risk factors. Fisher's exact test was used for comparing 12 month fusion rates by binary risk factors while exact chi-square tests were used for multi-category nominal or ordinal risk factors. Student's t-tests were used to compare continuous variables between groups (CBA volume comparisons), Generalized Estimating Equation (GEE) modeling was performed to compare joint-level fusion results by CBA group. Data are reported as mean $\pm \mathrm{SD}$. Two-sided p-values of less than 0.05 were considered significant.

\section{Results}

In the six-year interval (January 2009 and December 2014), there were a total of 299 patients that had fusion procedures performed. Of these, 148 patients were treated with CBA. Seventy-three patients were excluded because a concomitant bone growth product was used or because the subject did not return for the one-year follow up. Seventyfive subjects that had completed one year follow-up were retrospectively enrolled in the study that included 141 joint arthrodeses.

\section{Baseline characteristics}

Of the 75 subjects, $52 \%$ were female and $48 \%$ were male with the mean age being $52.4 \pm 14.6$ years [age range, 19 to 83 ] (Table 1). $\mathrm{T}_{\mathrm{EV}}$ and $\mathrm{T}_{\mathrm{EL}}$ were implanted into $44(58.7 \%)$ and 31 (41.3\%) subjects, respectively. No significant differences in the population treated with $\mathrm{T}_{\mathrm{EV}}$ or $\mathrm{T}_{\mathrm{EL}}$ were observed for mean age, gender, race, ethnicity, weight status, nicotine use or for subjects at least 65 years of age (Table 1). There were no significant differences between $\mathrm{T}_{\mathrm{EV}}$ and $\mathrm{T}_{\mathrm{EL}}$ for subjects diagnosed

\begin{tabular}{|c|c|c|c|c|}
\hline Demographic and Diagnosis & All Subjects & $\mathrm{T}_{\mathrm{EL}}$ & $T_{E V}$ & P- value ${ }^{A}$ \\
\hline Demographic & \multicolumn{3}{|c|}{$\mathrm{n}(\%)$} & \\
\hline \multicolumn{5}{|l|}{ Gender } \\
\hline Male & $36(48.0)$ & $17(54.8)$ & $19(43.2)$ & \multirow{2}{*}{0.36} \\
\hline Female & $39(52.0)$ & $14(45.2)$ & $25(56.8)$ & \\
\hline \multicolumn{5}{|l|}{ Weight Status (BMI) } \\
\hline Normal & $5(6.7)$ & $2(6.4)$ & $3(6.8)$ & \multirow{3}{*}{0.098} \\
\hline Overweight & $24(32.0)$ & $14(45.2)$ & $10(22.7)$ & \\
\hline Obese/Morbidly Obese & $46(61.3)$ & $15(48.4)$ & $31(70.5)$ & \\
\hline Diabetic & $27(36.0)$ & $7(22.6)$ & $20(45.5)$ & 0.053 \\
\hline Age $65+$ & $20(26.7 \%)$ & $5(16.1)$ & $15(34.1)$ & 0.11 \\
\hline Nicotine Users & $25(33.3)$ & $11(35.5)$ & $14(31.8)$ & 0.81 \\
\hline Revision Surgery & $8(10.7)$ & $7(22.6)$ & $1(2.3)$ & $0.0073^{*}$ \\
\hline \multicolumn{5}{|l|}{ Diagnosis } \\
\hline Osteoarthritis & $19(25.3)$ & $9(29.0)$ & $10(22.7)$ & \multirow{5}{*}{0.25} \\
\hline Charcot & $15(20.0)$ & $4(12.9)$ & $11(25.0)$ & \\
\hline Deformity & $24(32.0)$ & $8(25.8)$ & $16(36.4)$ & \\
\hline Trauma & $3(4.0)$ & $1(3.2)$ & $2(4.6)$ & \\
\hline Other & $14(18.7)$ & $9(29.0)$ & $5(11.4)$ & \\
\hline
\end{tabular}

${ }^{A}$ Fisher's exact test for binary variable, exact chi-square test for multi-category variable

Table 1: Demographics (75 subjects). 
Citation: Loveland JD, Waldorff El, He DY, Atkinson BL (2017)A Retrospective Clinical Comparison of Two Allogeneic Bone Matrices Containing Viable Osteogenic Cells in Patients Undergoing Foot and/or Ankle Arthrodesis. J Stem Cell Res Ther 7: 405. doi: 10.4172/2157-7633.1000405

Page 3 of 7

with osteoarthritis, diabetes, Charcot, deformity or trauma. There were no significant differences between $\mathrm{T}_{\mathrm{EV}}$ and $\mathrm{T}_{\mathrm{EL}}$ in the joints that were repaired (Table 2). No complications were reported intraoperatively.

\begin{tabular}{|c|c|c|c|c|}
\hline $\begin{array}{l}\text { Baseline Operative } \\
\text { Information }\end{array}$ & All & $\mid \begin{array}{c}T_{\text {EL }} \\
\text { (53 Joints) }\end{array}$ & (88 Joints) & P-value ${ }^{B}$ \\
\hline & \multicolumn{3}{|c|}{$\mathrm{N}(\%)$} & \\
\hline \multicolumn{5}{|l|}{ Joint(s) Repaired } \\
\hline Calceneocuboid & $15(10.6)$ & $3(5.7)$ & $12(13.6)$ & 0.42 \\
\hline Subtalar & $42(29.8)$ & $19(35.8)$ & $23(26.1)$ & 0.45 \\
\hline Talonavicular & $33(23.4)$ & $13(24.5)$ & $20(22.7)$ & 0.96 \\
\hline Tibiotalar & $13(9.2)$ & $4(7.6)$ & $9(10.2)$ & 0.58 \\
\hline Tarsal Metatarsal & $18(12.8)$ & $4(7.6)$ & $14(15.9)$ & 0.15 \\
\hline Navicular Cuneiform & $14(9.9)$ & $6(11.3)$ & $8(9.1)$ & 0.65 \\
\hline Other & $6(4.3)$ & $4(7.6)$ & $2(2.3)$ & 0.16 \\
\hline \multicolumn{5}{|c|}{ \# Joints Repaired in Subjects } \\
\hline Single & $33(44.0)$ & $15(48.4)$ & $18(40.9)$ & \multirow{4}{*}{$0.26^{\mathrm{A}}$} \\
\hline Double & $21(28.0)$ & $11(35.5)$ & $10(22.7)$ & \\
\hline Triple & $18(24.0)$ & $4(12.9)$ & $14(31.8)$ & \\
\hline Quadruple & $3(4.0)$ & $1(3.2)$ & $2(4.6)$ & \\
\hline
\end{tabular}

${ }^{A}$ Exact chi-square test

BTreatment main effect from GEE repeated measures models with respective joint repaired as outcome, and CBA type as an independent variable, compound symmetry correlation structure.

Table 2: Joints repaired (141 joints repaired)

\section{Fusion}

There were no significant $(\mathrm{p}>0.05)$ differences in the $\mathrm{T}_{\mathrm{EV}}$ or $\mathrm{T}_{\mathrm{EL}}$ graft volume that was implanted. On a per joint basis, the CBA volume mean and range was $3.8+/-2.1 \mathrm{cc}$ and $1.3-10.0 \mathrm{cc}$, for the two graft types, respectively. The mean volume of $\mathrm{T}_{\mathrm{EV}}$ and $\mathrm{T}_{\mathrm{EL}}$ was nearly significant $(\mathrm{p}=0.086)$ greater in joints that did not fuse as compared to joints that did fuse (6.2 cc vs. $4.3 \mathrm{cc}$, respectively).

For the overall population $\left(\mathrm{T}_{\mathrm{EV}}\right.$ and $\mathrm{T}_{\mathrm{EL}}$ ) at 3,6 and 12 months, successful radiographic fusion was demonstrated in 57.3, 79.4 and 93.3\% of subjects, respectively, and 58.9, 83.9 and $95.7 \%$ of joints, respectively (Figures 1-3 and Table $3 \mathrm{~A}$ and $3 \mathrm{~B}$ ). Also, there were no significant differences in fusion rates between $\mathrm{T}_{\mathrm{EV}}$ and $\mathrm{T}_{\mathrm{EL}}$ at any timepoint (Table 3A and 3B). Of the eight revision surgeries that were entered into the study and implanted with CBA, 7 were fused $(87.5 \%)$ at 12 months.

Among the overall population with clinical risk factors, there were no significant $(\mathrm{p}>0.05)$ differences detected in fusion rates among subjects who were diabetic, at least 65 years of age, or obese/morbidly obese as compared to those who were not at any time point (Table 4). Similarly, there were no significant $(\mathrm{p}>0.05)$ differences in fusion rates between $\mathrm{T}_{\mathrm{EV}}$ and $\mathrm{T}_{\mathrm{EL}}$ in each of these groups (Table 5).

In the overall population, there were no significant $(\mathrm{p}>0.05)$

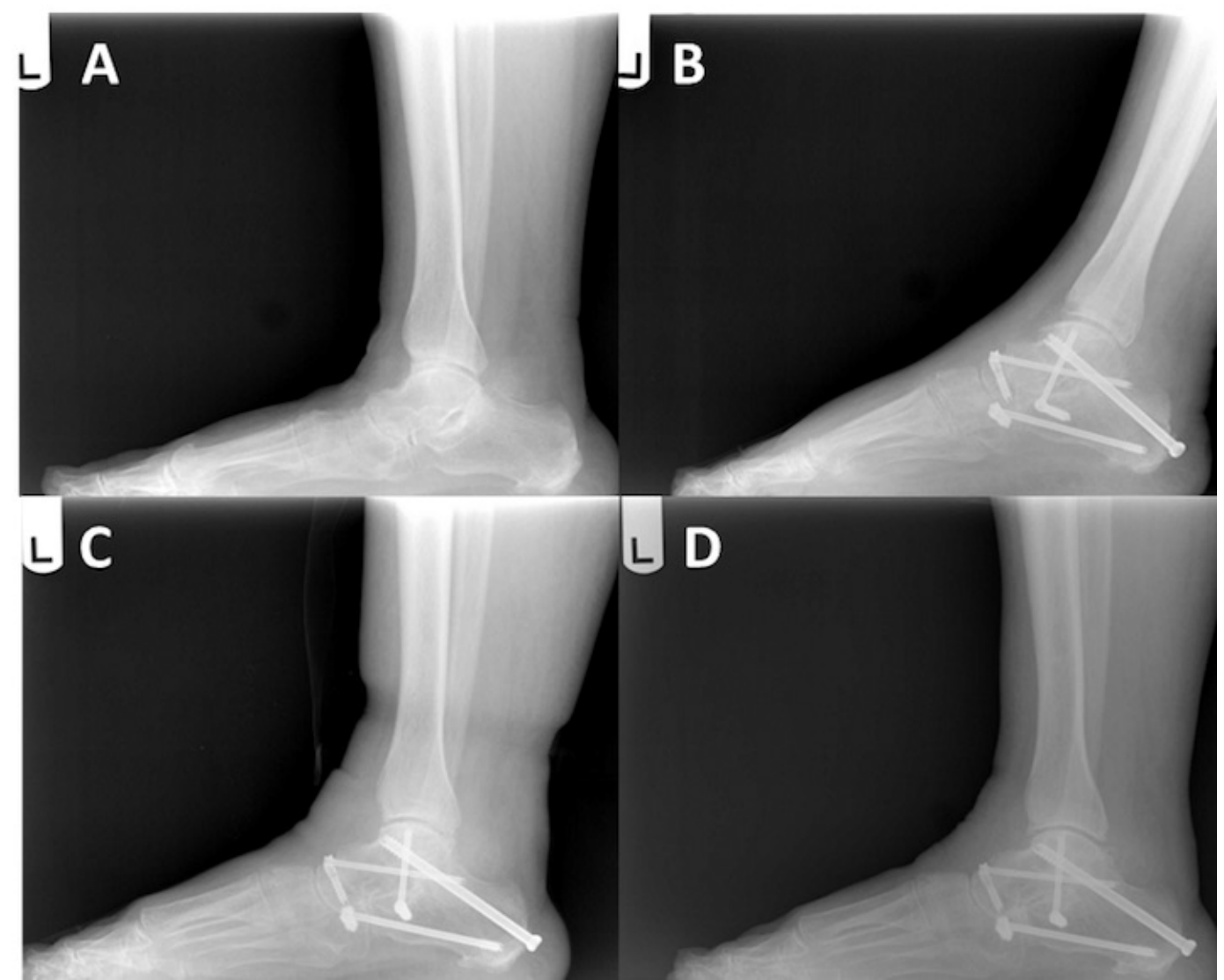

Figure 1: Triple arthrodesis using Trinity Evolution (TEV). Triple arthrodesis using TEV for a 66-year-old obese female diagnosed with arthritic flatfoot deformity. (A) Baseline, (B) 3, (C) 6 and (D) 12 months. Fusion was observed at 3 months. 

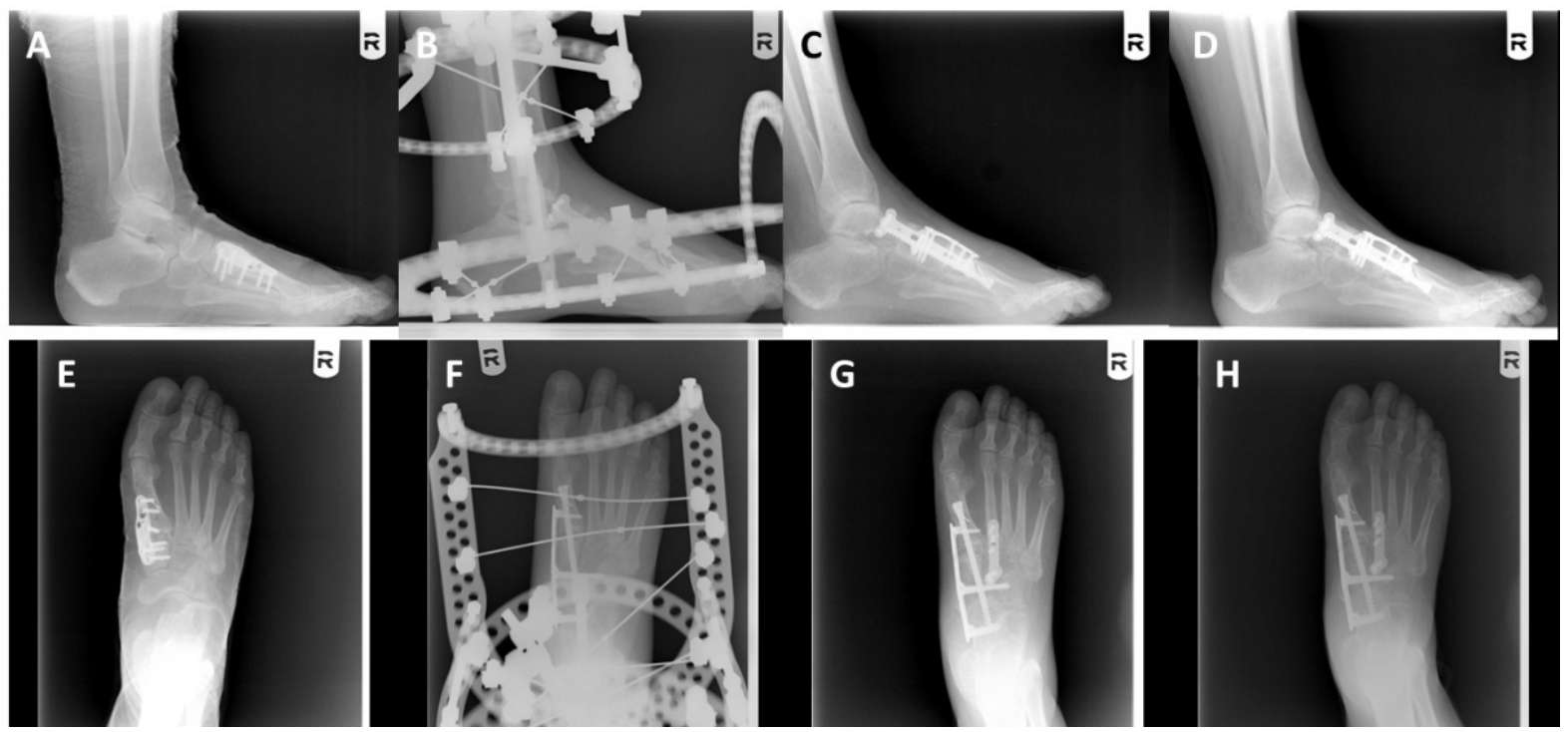

Figure 2: Trinity ELITE (TEL) used in talonavicular and navicular cuneiform arthrodesis. Talonavicular and navicular cuneiform arthrodesis using TEL of a 37-yearold obese, diabetic female diagnosed with Charcot foot. $(A, E)$ Baseline, $3(B, F), 6(C, G)$ and $12(D, H)$ months. Fusion was observed at 3 months.

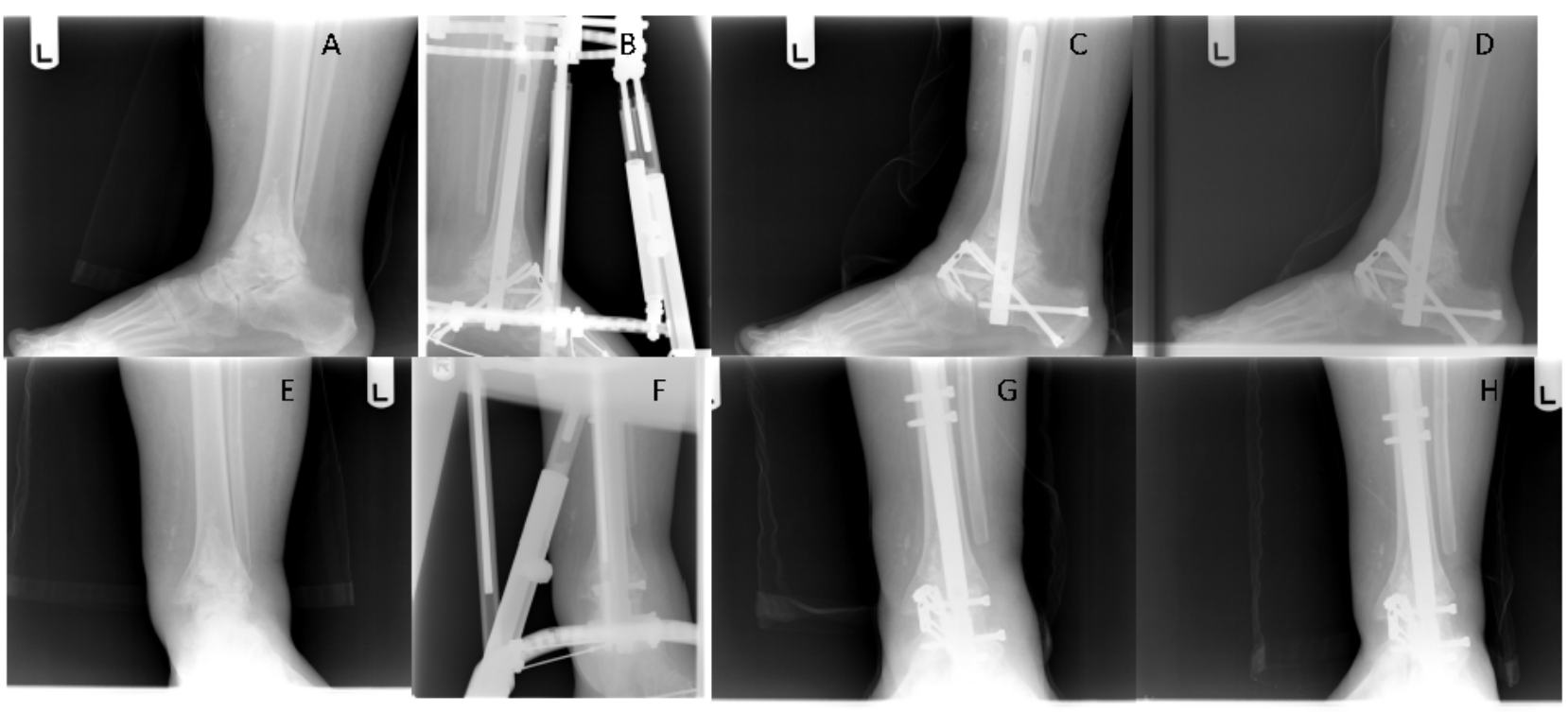

Figure 3: Triple arthrodesis using Trinity ELITE (TEL). Triple arthrodesis (tibiotalar, talonavicular and subtalar) using TEL of a 50-year-old obese female with some history of neuropathy in the lower extremities who had a previous non-union. The tibiotalar joint was fused at 3 months and all three joints were fused by 12 months. $(\mathrm{A}, \mathrm{E})$ Baseline, $3(\mathrm{~B}, \mathrm{~F}), 6(\mathrm{C}, \mathrm{G})$ and $12(\mathrm{D}, \mathrm{H})$ months.

\begin{tabular}{|c|c|c|c|c|}
\hline \multirow[t]{2}{*}{ Visit } & \multicolumn{4}{|c|}{ Fused $/ \mathrm{n}(\%)$ Fused (95\% exact $\mathrm{Cl})$} \\
\hline & Overall & $\begin{array}{c}\text { Treated with Trinity } \\
\text { Evolution }\end{array}$ & $\begin{array}{c}\text { Treated with Trinity } \\
\text { ELITE }\end{array}$ & P-Valu \\
\hline Month 3 & $\begin{array}{c}43 / 75 \\
57.3(45.4,68.7)\end{array}$ & $\begin{array}{c}24 / 44 \\
54.6(38.9,69.6)\end{array}$ & $\begin{array}{c}19 / 31 \\
61.3(42.2,78.2)\end{array}$ & 0.64 \\
\hline Month 6 & $\begin{array}{c}54 / 68 \\
79.4(67.9,88.3)\end{array}$ & $\begin{array}{c}32 / 41 \\
78.1(62.4,89.4)\end{array}$ & $\begin{array}{c}22 / 27 \\
81.5(61.9,93.7)\end{array}$ & 1.00 \\
\hline Month 12 & $\begin{array}{c}70 / 75 \\
93.3(85.1,97.8)\end{array}$ & $\begin{array}{c}41 / 44 \\
93.2(81.3,98.6)\end{array}$ & $\begin{array}{c}29 / 31 \\
93.6(78.6,99.2)\end{array}$ & \\
\hline
\end{tabular}

AFisher's exact test

Table 3A: Per subject fusion rates for 75 subjects.

\begin{tabular}{|c|c|c|c|c|}
\hline Visit & \multicolumn{2}{|c|}{ Fused/n (\%) Fused (95\% exact Cl) } & P-value $^{\mathbf{B}}$ \\
\hline & Overall & $\begin{array}{c}\text { Treated with } \\
\text { Trinity Evolution }\end{array}$ & $\begin{array}{c}\text { Treated with } \\
\text { Trinity ELITE }\end{array}$ & \\
\hline Month 3 & $83 / 141(58.9)$ & $49 / 88(55.7)$ & $34 / 53(64.2)$ & 0.34 \\
\hline Month 6 & $109 / 130(83.9)$ & $69 / 84(82.1)$ & $40 / 46(87.0)$ & 0.58 \\
\hline Month 12 & $135 / 141(95.7)$ & $84 / 88(95.5)$ & $51 / 53(96.2)$ & 0.84 \\
\hline
\end{tabular}

${ }^{B}$ Treatment main effect from GEE repeated measures models with respective fusion status as outcome, and CBA type as an independent variable, compound symmetry correlation structure.

Table 3B: Per joint fusion rates for 141 arthrodeses. 


\begin{tabular}{|c|c|c|}
\hline Risk Factor & Subjects Fused/ Total Subjects & P-value \\
\hline Weight Status & $5 / 5(100)$ & \multirow{2}{*}{0.22} \\
\hline Normal & $24 / 24(100)$ & \\
\hline $\begin{array}{c}\text { Overweight } \\
\text { Obese/ } \\
\text { Morbidly obese }\end{array}$ & $41 / 46(89.1)$ & \\
\hline Diabetes & & \multirow{2}{*}{1.00} \\
\hline No & $45 / 48(93.8)$ & \\
\hline Yes & $25 / 27(92.6)$ & \multirow{2}{*}{0.32} \\
\hline Age & & \\
\hline Less than 65 year & $50 / 55(90.9)$ & \\
\hline $65+$ & $20 / 20(100)$ & \multirow{2}{*}{0.040} \\
\hline Nicotine Use & & \\
\hline No & $49 / 50(98.0)$ & \\
\hline Yes & $21 / 25(84.0)$ \\
\hline
\end{tabular}

Table 4: Subject fusion rates and associated risk factors at 12 months $(75$ subjects).

\begin{tabular}{|c|c|c|c|}
\hline Risk Factor & \multicolumn{2}{|c|}{ Subjects fused overall } & \\
\hline Age 65+ & $\begin{array}{c}\text { Treated with Trinity } \\
\text { Evolution Fused/n (\%) }\end{array}$ & $\begin{array}{c}\text { Treated with Trinity ELITE } \\
\text { Fused/n (\%) }\end{array}$ & P- Value \\
\hline $\begin{array}{c}\text { Obese/ } \\
\text { Morbidly } \\
\text { Obese }\end{array}$ & $15 / 15(100)$ & $5 / 5(100)$ & 1.00 \\
\hline $\begin{array}{c}\text { Current } \\
\text { Nicotine User }\end{array}$ & $12 / 14(85.7)$ & $13 / 15(86.7)$ & 1.00 \\
\hline Diabetic & $19 / 20(95.0)$ & $9 / 11(81.8)$ & 1.00 \\
\hline
\end{tabular}

Table 5: Comparison of fusion rates for Trinity Evolution and Trinity ELITE in subjects with risk factors.

differences detected in fusion rates between males and females or for subjects that received 1, 2, 3 or 4 arthrodeses. There were also no significant $(\mathrm{p}>0.05)$ differences in the per joint or subject fusion rate among subjects for the specific joints repaired (calcaneocuboid, subtalar, talonavicular, etc.). Similarly, there were no significant ( $\mathrm{p}>0.05$ ) differences between fusion rates for $\mathrm{T}_{\mathrm{EV}}$ and $\mathrm{T}_{\mathrm{EL}}$ within each of these groups (Table 5).

\section{Discussion}

This retrospective open-label study compared the fusion rates between two Cellular Bone Allografts (CBA) in foot and/or ankle arthrodeses. Subjects with risk factors were not excluded from the study and there were no restrictions placed on the subject diagnosis or operative procedure in order to simulate everyday foot and ankle specialty practice. The usage of CBA did not raise any safety concerns since there were no infections that were attributed to the graft material.

To our knowledge, this is the first study to compare the fusion rates of two different CBAs. Both CBAs consist of two components: cancellous bone that contain viable osteogenic cells and demineralized cortical bone. However, the formulations of the two CBAs are different and $\mathrm{T}_{\mathrm{EL}}$ contains demineralized bone fibers that inherently entangle with one another, while $\mathrm{T}_{\mathrm{EV}}$ contains small demineralized particles. This difference in composition allows $\mathrm{T}_{\mathrm{EL}}$ to be more cohesive which may lead to less loss of graft material upon delivery and a higher graft density in the target site. $\mathrm{T}_{\mathrm{EL}}$ also has a validated, two-fold higher minimum number of MSCs and/or osteoprogenitor cells than $T_{E V}(\geq 100,000 / c c$ vs. $\geq 50,000 /$ cc cells, respectively). Although the minimum cell number was higher in $\mathrm{T}_{\mathrm{EL}}$, there were no differences in fusion rates as compared to $\mathrm{T}_{\mathrm{EV}}$. Similarly, a study that evaluated the number of bone marrow aspirate cells delivered in foot and ankle arthrodeses demonstrated no correlation in the minimum number of cells that were associated with a successful fusion [20]. We speculate that both the minimum 50,000 and 100,000 mesenchymal stem cells (MSC) and/or progenitor cells found in $\mathrm{T}_{\mathrm{EV}}$ and $\mathrm{T}_{\mathrm{EL}}$, respectively, are above the threshold required to achieve a successful fusion. Appropriately powered studies would be required to determine if $\mathrm{T}_{\mathrm{EL}}$ accelerates the fusion rate as compared to $\mathrm{T}_{\mathrm{EV}}$

The optimal MSC dose for effective fusion of foot and ankle joints is not known and this is the first clinical study to evaluate the impact of different MSC quantities in this indication. In CBA, the potential range of MSC dose is limited by the physiologic MSC quantities in the human donor bone. Clinical evaluation of supraphysiologic doses of MSCs (often greater than two logs above the physiologic amount of MSCs in bone) are currently underway to evaluate the effect on fusion rates in several indications. In lieu of published Phase III clinical studies, a large animal study demonstrated that although the addition of MSCs resulted in increased fusion rates compared to the control, there were no conclusive effects of cell dose over a 9-fold range on fusion rates [21]. This latter study confirms that there is a minimum cell dose that is effective and more MSCs do not necessarily equate to higher fusion rates. Although the reason for this is not known, some authors have speculated that there is a minimum number of MSCs that are necessary to enhance the healing cascade [20] and that more MSCs may lead to overpopulation and rapid depletion of nutrients within the graft area [22].

An additional aim of this study was to determine if CBA would be as effective in patients with significant risk factors as compared to normal healthy subjects. Risk factors such as advanced age, diabetes, obesity and osteoporosis, are associated with compromised physiological activities. Each of these risk factors have been postulated to potentially have a negative impact on bone healing and are associated with lower fusion rates [5-7,23-25]. This study sought to stratify these groups out of the entire population and determine if fusion rates and clinical outcomes would be impacted. Similar to the Jones, et al. [18], study, the current study demonstrated no notable differences in fusion rates between normal and groups with risk factors. No significant differences in fusion rates were observed between subjects that had diabetes, were greater than 65 years of age, or were obese /morbidly obese as compared to those that were not. Thus, this study confirms the findings from the prior study that CBA may mitigate the increased risk of nonunion for subjects with compromised physiologic activities, although a randomized, controlled study with comparisons made between normal subjects and those with risk factors would be required to draw any definitive conclusions.

The compromised physiologic activities and increased nonunion rates in patients with significant risk factors such as diabetes may be caused, at least in part, by impaired osteoclast and osteoblast functions [26-31]. CBA contains viable MSCs which are capable of proliferation and osteogenic differentiation [32] and may help overcome the cellular limitations of diabetes.

There are other risk factors for nonunions, such as Charcot neuropathy, which is a challenging environment for bone healing due to poor bone quality and poor vascularity. A recent systematic review of 860 patients with Charcot neuropathy demonstrated an overall amputation rate of $8.9 \%$ [33]. In contrast, the current study demonstrated a $0 \%$ amputation rate and a $100 \%(15 / 15)$ fusion rate for these patients 
treated with CBA. Since there were no significant difference in fusion rates for patients with and without Charcot neuropathy, CBA may help overcome this challenging environment for bone healing. In addition, an attempted revision has been previously identified as a significant risk factor for persistent nonunion and a $77 \%$ fusion rate resulted following revisional arthrodesis of the foot and ankle [32]. Although the sample size was small, the current study demonstrated a substantially higher fusion rate, $87.5 \%(7 / 8)$, following revisional surgery.

Autologous corticocancellous bone graft (autograft) placed between the joint surfaces to be fused, has historically been the gold standard [9-11]. However, since harvesting autograft bone results in well-known complications [12-15], CBA has been used since it lacks the patient morbidity associated with autograft harvest yet shares the three characteristics that are required for effective bone formation, an osteoconductive scaffold, osteoinductive growth factors and osteogenic cells. In a previous publication, the fusion rate using CBA after foot and/or ankle arthrodesis was higher than or comparable to historical autograft fusion rates [18]. For autograft, the per subject fusion rates were $66.4 \%(91 / 137)$ and $75.2 \%(103 / 137)$ at 6 and 12 months, respectively [2]. In comparison, for subjects who received CBA in the current study, the per subject fusion rates were 79.4\% (54/68) and $93.3 \%$ (70/75) at 6 and 12 months, respectively indicating that use of CBA may result in increased fusion rates compared to autograft.

The importance of a sufficient volume of graft material in achieving foot or ankle fusion was previously described [34,35]. That study demonstrated a decrease in fusion rate with increased volume of graft material. The current study confirms these findings because the estimated per joint CBA volume was nearly significantly greater in joints that did not fuse as compared to joints that did fuse $(6.2 \mathrm{cc}$ versus $4.3 \mathrm{cc}$, respectively). The reason for this is unknown, although some possible explanations are that larger defects may be more difficult to heal or over packaging of a joint may hinder the healing process by inhibiting cellular ingrowth and repair.

Because this was a single center study with one surgeon, one limitation of the study was that alternative operative approaches or fixation were not evaluated. Furthermore, the surgeon determined the fusion status and surgeon bias is known with respect to consideration of other clinical outcome parameters. This potential bias was mitigated because of the comparative nature of the study in which the same surgeon evaluated both CBA treatments. An additional limitation of the study was that fusion was assessed solely by radiographs because the surgeon's standard of care did not utilize thin cut Computed Tomography (CT). Another potential limitation of the study is the 4-month window utilized for the 12 month timepoint. Since both $\mathrm{T}_{\mathrm{EV}}$ or $\mathrm{T}_{\mathrm{EL}}$ groups utilized the same window, this does not affect the comparative conclusions. In addition, this 4-month window is relatively narrow compared to recently published retrospective studies that utilized windows ranging from $16-48$ months $[34,36,37]$. Lastly, retrospective studies have the potential for selection bias. For this study, there was the potential for selection bias of subjects that received either $\mathrm{T}_{\mathrm{EV}}$ or $\mathrm{T}_{\mathrm{EL}}$ and/or for subjects that were retrospectively recruited into the study. The decision to utilize $\mathrm{T}_{\mathrm{EV}}$ and $\mathrm{T}_{\mathrm{EL}}$ was solely based on commercial availability and thus there was no selection bias in subjects that were treated with different forms of CBAs. The 75 subjects recruited into this study were part of a larger pool of patients that received arthrodesis, but that did not receive CBA. The treating surgeon's standard of care is to use CBA on subjects with risk factors and thus the selection bias to use CBA was for subjects that had an increased risk of nonunion.
The results of this clinical evaluation suggest that CBAs are safe and effectively achieve fusion in foot and/or ankle arthrodeses. Both $\mathrm{T}_{\mathrm{EV}}$ and $\mathrm{T}_{\mathrm{EL}}$ have validated BMP-2 content and the minimum threshold cell numbers to achieve high rates of fusion in a broad patient population, including those at risk for nonunion and older patients representative of the Medicare population. These CBAs have the biological properties of autograft bone, but lack the donor site morbidity associated with harvesting autogenous bone and thus provide advantages to the patient and the surgeon. Appropriately powered randomized controlled studies comparing $\mathrm{T}_{\mathrm{EV}}$ and/or $\mathrm{T}_{\mathrm{EL}}$ to autograft are warranted in the future.

\section{Conclusions}

Both $\mathrm{T}_{\mathrm{EV}}$ and $\mathrm{T}_{\mathrm{EL}}$ contain the threshold number of viable osteogenic cells to achieve high rates of foot and ankle arthrodesis in healthy subjects and in subjects with risk factors for nonunion making these graft materials a valuable biological adjunct for the foot and ankle surgeon. The results of this investigation could be used in the development of future randomized controlled trials or prospective cohort studies that focus on foot and /or ankle arthrodeses.

\section{Declarations}

The Institutional Review Board approved the study and informed consent was waived for subjects.

\section{Availability of Data and Material}

The datasets used and/or analyzed during the current study are available from the corresponding author on reasonable request.

\section{Competing Interests}

EIW is a stockholder and employee of Orthofix. JDL is a funded investigator by Orthofix. BLA and DYH report personal fees from Orthofix during the conduct of the study.

\section{Funding}

The study was supported by a grant from Orthofix who also supported the study design and the collection, analysis and interpretation of data and manuscript preparation.

\section{Author's Contributions}

JDL participated in the surgical procedures, data analysis and acquisition and critical revisions. DYH was responsible for the data analysis. EIW participated in the conception and design of the study and was involved in the data analysis and critical revisions. BLA was involved in the manuscript writing, literature search, and data interpretation. All authors read and approved the final manuscript.

\section{Acknowledgements}

The authors acknowledge the contributions of Johnnie Maynard for data collection

\section{References}

1. Best MJ, Buller LT, Miranda A (2015) National Trends in Foot and Ankle Arthrodesis: 17-year analysis of the national survey of ambulatory surgery and national hospital discharge survey. J Foot Ankle Surg 54: 1037-1041. [PubMed]

2. DiGiovanni CW, Lin SS, Baumhauer JF, Daniels T, Younger A, et al. (2013) Recombinant human platelet-derived growth factor-BB and beta-tricalcium phosphate (rhPDGF-BB/b-TCP): an alternative to autogenous bone graft. JBJS 95: 1184-1192. [PubMed]

3. Abidi NA, Gruen GS, Conti SF (2000) Ankle arthrodesis: indications and techniques. J Am Acad Orthop Surg 8: 200-209. [PubMed]

4. Mann RA, Rongstad KM (1998) Arthrodesis of the ankle: a critical analysis Foot Ankle Int 19: 3-9. [PubMed] 
5. Perlman MH, Thordarson DB (1999) Ankle fusion in a high risk population: an assessment of nonunion risk factors. Foot Ankle Int 20: 491-496. [PubMed]

6. Rabinovich RV, Haleem AM, Rozbruch SR (2015) Complex ankle arthrodesis: a review of the literature. World J Orthop 6: 602-613. [PubMed]

7. Thevendran G, Wang C, Pinney SJ, Penner MJ, Wing KJ, et al. (2015) Nonunion risk assessment in foot and ankle surgery: proposing a predictive risk assessment model. Foot Ankle Int 36: 901-907. [PubMed]

8. Thevendran G, Younger A, Pinney S (2012) Current concepts review: risk factors for nonunions in foot and ankle arthrodesis. Foot Ankle Int 33: 10311040. [PubMed]

9. Amer JW, Santrock RD (2014) A historical review of common bone graft materials in foot and ankle surgery. Foot Ankle Spec 7: 143-151. [PubMed]

10. DiDomenico LA, Thomas ZM (2015) Osteobiologics in foot and ankle surgery. Clin Podiatr Med Surg 32: 1-19. [PubMed]

11. Lareau CR, Deren ME, Fantry A, Donahue Rm DiGiovanni CW (2015) Does autogenous bone graft work? A logistic regression analysis of data from 159 papers in the foot and ankle literature. Foot Ankle Surg 21: 150-159. [PubMed]

12. Boone DW (2003) Complications of iliac crest graft and bone grafting alternatives in foot and ankle surgery. Foot Ankle Clin 8: 1-14. [PubMed]

13. Chou LB, Mann RA, Coughlin MJ, McPeake WT, Mizel MS (2007) Stress fracture as a complication of autogenous bone graft harvest from the distal tibia. Foot Ankle Int 28:199-201.

14. Kirmeier R, Payer M, Lorenzoni M, Wegscheider WA, Seibert FJ, et al. (2007) Harvesting of cancellous bone from the proximal tibia under local anesthesia: donor site morbidity and patient experience. J Oral Maxillofac Surg 65: 22352241. [PubMed]

15. Summers BN, Eisenstein SM (1989) Donor site pain from the ilium. A complication of lumbar spine fusion. JBJS 71: 677-680. [PubMed]

16. Brydone AS, Meek D, Maclaine S (2010) Bone grafting, orthopaedic biomaterials, and the clinical need for bone engineering. Proc Inst Mech Eng $\mathrm{H}$ 224: 1329-1343. [PubMed]

17. Park JJ, Hershman SH, Kim YH (2013) Updates in the use of bone grafts in the lumbar spine. Bull Hosp Joint Dis 71: 39-48. [PubMed]

18. Jones CP, Loveland J, Atkinson BL, Ryaby JT, Linovitz RJ, et al. (2015) Prospective, multicenter evaluation of allogeneic bone matrix containing viable osteogenic cells in foot and/or ankle arthrodesis. Foot Ankle Int 36: 1129-1137. [PubMed]

19. Rush SM (2010) Trinity Evolution. Mesenchymal stem cell allografting in foot and ankle surgery. Foot Ankle Spec 3: 140-143. [PubMed]

20. McAlister JE, Hyer CF, Berlet GC, Collins CL (2015) Effect of osteogenic progenitor cell concentration on the incidence of foot and ankle fusion. J Foot Ankle Surg 54: 888-891. [PubMed]

21. Wheeler DL, Lane JM, Seim HB, Puttlitz CM, Itescu S, et al. (2014) Allogeneic mesenchymal progenitor cells for posterolateral lumbar spine fusion in sheep. Spine J 14: 435-444. [PubMed]

22. Liebergall M, Schoeder J, Mosheiff R, Gazit Z, Yoram Z, et al. (2013) Stem cell-based therapy for prevention of delayed fracture union: a randomized and prospective preliminary study. Mol Ther 21: 1631-1638. [PubMed]
23. Chahal J, Stephen DJ, Bulmer B, Daniels T, Kreder HJ (2006) Factors associated with outcome after subtalar arthrodesis. J Orthop Trauma 20: 555561. [PubMed]

24. Easley ME, Trnka HJ, Schon LC, Myerson MS (2000) Isolated subtalar arthrodesis. JBJS 82: 613-624. [PubMed]

25. Flemister AS, Infante AF, Sanders RW, Walling AK (2000) Subtalar arthrodesis for complications of intra-articular calcaneal fractures. Foot Ankle Int 21: 392399. [PubMed]

26. Inaba M, Terada M, Koyama H, Yoshida O, Isimura E, et al. (1995) Influence of high glucose on 1,25-dihydroxyvitamin D3-induced effect on human osteoblastlike MG-63 cells. J Bone Miner Res 10:1050-1056. [PubMed]

27. Inaba M, Nishizawa Y, Mita K, Kumeda Y, Emoto M, et al. (1999) Poor glycemic control impairs the response of biochemical parameters of bone formation and resorption to exogenous 1,25-dihydroxyvitamin D3 in patients with type 2 diabetes. Osteoporos Int 9: 525-531. [PubMed]

28. Jones KB, Maiers-Yelden KA, Marsh JL, Zimmerman MB, Estin M, et al. (2005) Ankle fractures in patients with diabetes mellitus. JBJ 87:489-495. [PubMed]

29. Kasahara T, Imai S, Kojima H, Katagi M, Kimura H, et al. (2010) Malfunction of bone marrow derived osteoclasts and the delay of bone fracture healing in diabetic mice. Bone 47: 617-25. [PubMed]

30. Khazai NB, Beck GR Jr, Umpierrez GE (2009) Diabetes and fractures: an overshadowed association. Curr Opin Endocrinol Diabetes Obes 16: 435 [PubMed]

31. Massé PG, Pacifique MB, Tranchant $\mathrm{CC}$, Arjmandi $\mathrm{BH}$, Ericson $\mathrm{KL}$, et al. (2010) Bone metabolic abnormalities associated with well-controlled type 1 diabetes (IDDM) in young adult women: a disease complication often ignored or neglected. J Am Coll Nutr 29:419-429. [PubMed]

32. Neman J, Duenas V, Kowolik CM, Hambrecht AC, Chen MY, et al. (2013) Lineage mapping and characterization of the native progenitor population in cellular allograft. Spine J 13: 162-174. [PubMed]

33. Schneekloth BJ, Lowery NJ, Wukich DK (2016) Charcot neuroarthropathy in patients with diabetes: an updated systematic review of surgical management. J Foot Ankle Surg 55: 586-590. [PubMed]

34. O'Connor KM, Johson JE, McCormick JJ, Klein SE (2016) Clinical and operative factors related to successful revision arthrodesis in the foot and ankle. Foot Ankle Int 37: 808-815. [PubMed]

35. DiGiovanni CH, Lin SS, Daniels TR, Glazebrook M, Evangelista P, et al. (2016) The importance of sufficient graft material in achieving foot or ankle fusion. JBJS 98: 1260-1267. [PubMed]

36. Sundararajan SR, Srikanth KP, Nagaraja HS, Rajasekaran S, et al. (2017) Effectiveness of hindfoot arthrodesis by stable internal fixation in various Eichenholtz stages of neuropathic ankle arthropathy. J Foot Ankle Surg. 56: 282-286. [PubMed]

37. Thomas AE, Guyver PM, Taylor JM, Czipri M, Talbot NJ, et al. (2015) Tibiotalocalcaneal arthrodesis with a compressive retrograde nail: a retrospective study of 59 nails. Foot Ankle Surg. 21: 202-205. [PubMed] 